\title{
Data Venia: Comentários sobre "Como Falar em Paradigmas da Educação ", de A.A. Rubim
}

\section{Tarso Bonilha Mazzotti}

Universidade Federal do Rio de Janeiro (UFRJ)

O doutor Rubim apóia-se em Tomás de Aquino para afirmar o que deveria ser compreendido como paradigma da Educação. Pode-se aceitar ou não o tomismo. Certamente o doutor Rubim tem todo o direito de assumir a posiço que assume. Pode, inclusive, sustentar que sua posição é a única verdadeira, e não se teria qualquer outro critério para confirmar a validade de suas proposições, a não ser o magister dixit. A impossibilidade de decidir qual aposição correta constitui o principal problema da investigação, não apenas em Educação mas em todas as ciências, humanas ou não. Esta é, aliás, a principal questão de interesse de Kuhn, e não se sabe se uma dada ciência é ou não "paradigmática ". Por outro lado, no que se refere à Educação, não seria preciso instituir uma "antropologia filosófica" que dê sentido único à noção de paradigma, como quer o doutor Rubim. O problema central das epistemologias, hoje, está na determinação da possibilidade da indução, ou seja, se é possível construir modelos adequados ao real a partir de nossas experiências, como tem sido debatido no âmbito de todas as ciências contemporâneas. E o que procuramos mostrar nestes comentários.

Achylle Alexio Rubim em sua participação no debate sobre Paradigmas em Educação (Revista Brasileira de Estudos Pedagógicos, v.74, n.177, p.425-443) comenta, na esteira de outros, a polissemia da noção de "paradigma"1 proposta por Thomas Kuhn.

${ }^{1}$ A polissemia da noção de "paradigma" na obra de Khun foi rastreada por Masterson (1979). 
A partir da exaustivamente comentada polissemia da noção kuhniana de paradigma, Rubim resolveu apresentar sua visão deste conceito no que se refere à Educação. Para o doutor Rubim, a Educação - como conhecimento sistematizado - só poderia se utilizar da noção proposta por ele; daí o título de seu trabalho "Como falar em Paradigmas em Educação". Estes "paradigmas" só poderiam ter uma fonte, pois para o doutor Rubim: "Parece óbvio que os paradigmas da educação deveriam brotar de uma antropologia" (p.429). Uma "antropologia filosófica" que consideraria os "aspectos qualitativos" do humano, em oposição ao "quantitativo" do "deslumbramento técnico-científico" que, por sua natureza, se esquece das "dimensões essenciais do homem, como a consciência, a liberdade, a orientação para o bem, o sentido da vida e, finalmente, a dimensão espiritual". Mais adiante, afirma:

... É verdade que são perenes esses elementos, valem para o homem babilônico como para o homem atual.

Não é, de todo, verdade. A "liberdade" enquanto prática e conceito emerge em um dado momento histórico no Ocidente: o da sociedade grega composta por guerreiros que eram iguais e livres por serem guerreiros. O "homem" grego antigo é o "cidadão" que contribui com seus bens, força física e astúcia ao empreendimento da guerra. Todos os demais não são livres, nem são "homens". Seria anacrônico dizer que a noção de liberdade expressa pelos gregos antigos é a mesma que hoje utilizamos, é errado sustentar que os orientais, os babilónicos em particular, apresentavam aquela noção.

Há, no entanto, algo que parece ser permanente e que pode ser expresso na aparente perplexidade de Karl Marx diante da arte grega:

... a dificuldade não está em compreender que a arte grega e a epopéia estão ligadas a certas formas de desenvolvimento sociais. Eis a dificuldade: elas nos causam ainda um prazer artístico e, de um certo modo, nos servem de norma, são para nós um modelo inacessível.

Vernant e Vidal-Naquet comentam essa passagem da Introdução à Economia Politica, mostrando que a solução do enigma está na mesma 
obra, quando Marx assinala que "a educação dos cinco sentidos seria obra da história universal"; ou ainda: "O olho humano tal como seu objeto se torna um objeto social, humano, vindo do homem e terminando no homem". Dessa maneira, "os sentidos se tornaram 'teóricos' em sua ação imediata" (Marx apud Vernant e Vidal-Naquet, 1991, p.88). Vernant e Vidal-Naquet avaliam essa posição como sendo uma "fórmula admirável por sua modernidade" e, mais adiante (p.96):

... O drama antigo explora os mecanismos pelos quais um indivíduo, por melhor que seja, é conduzido à perdição, não pelo domínio da coação, nem pelo efeito de sua perversidade ou de seus vícios, mas em razão de uma falta, de um erro, que qualquer um pode cometer. Desse modo, ela desnuda o jogo de forças contraditórias a que o homem está submetido, pois toda sociedade, toda cultura, da mesma forma que a grega, implica em tensões e conflitos. Dessa forma, a tragédia propõe ao espectador uma interrogação sobre a condição humana, seus limites, sua finitude necessária.

A tragédia e as demais formas artísticas nos tocariam por sermos produzidos, também, pela ação artística, ou como Vernant e Vidal-Naquet dizem:

... Em arte, a produção não produz apenas um "objeto para o sujeito", mas um "sujeito para o objeto" — esse objeto novo que acaba de ser criado ${ }^{2}$.

A tragédia ainda nos comove não porque temos a mesma noção de "bem", os mesmos valores dos gregos antigos, mas por apresentar um simulacro das circunstâncias que expressa as estruturas fundamentais de qualquer conflito humano. Daí a permanente interpretação e reinterpretação $^{3}$ das tragédias, dos mitos gregos antigos. Somos educados por meio das tragédias gregas, dos épicos gregos, dos mitos gregos; vemos nosso mundo atual pela estrutura das significações que damos a essas fontes de nossa cultura (ocidental), assimiladas e acomodadas - adaptadas - ao nosso tempo, ao nosso modo de vida contemporâneo.

\footnotetext{
${ }^{2}$ Na mesma obra, um pouco mais adiante, os autores afirmam que o mesmo ocorre com as ciências (p.89).

${ }^{1}$ Como, por exemplo, a reinterpretação que Freud deu ao mito e à tragédia de Édipo, a qual, de fato, em nada se assemelha ao espírito grego.
} 
Parece, no entanto, que o doutor Rubim desconhece os trabalhos dos helenistas que têm demonstrado, nos mais diversos setores, as particularidades do chamado "espírito grego" que está no princípio da cultura ocidental e, ao mesmo tempo, demonstra quão distantes somos dos nossos ancestrais. Bastaria examinarmos algumas obras de helenistas contemporâneos para não nos deixarmos conduzir pelo "essencialismo" que o doutor Rubim sustenta. Não há, de fato, "natureza humana", algo que seria "eterno", "permanente", como deseja o doutor Rubim. Mesmo sendo herdeiros dos gregos, não somos gregos, não partilhamos, por exemplo, da "natureza" guerreira de Atenas, de Esparta, de Mileto; mesmo sendo latinos, não somos romanos...

Tomemos-se a noção de democracia, forma de governo que garantiria a liberdade de "todos e cada um" ${ }^{4}$ dos cidadãos. Em Atenas a democracia $^{5}$ significava a exclusão da grande maioria de homens e mulheres, mas não apenas isto; significava que o voto na Assembléia por uma proposição no sentido de se declarar guerra a Esparta, por exemplo, envolveria, pessoalmente, cada cidadão na guerra, que entregaria seus bens, escravos e a própria vida para o combate. E muito diverso da democracia representativa que delega a ação para um grupo de homens, como ocorre em nossos dias. Essa prática social não nos faz diversos dos cidadão gregos? Por certo que sim. Nós tendemos a "não nos metermos em política", enquanto que o ateniense vivia da e na política. Os exemplos poderiam ser multidões, mas basta este.

Todavia o "homem" não é apenas ocidental. Há homens em muitos outros recantos do mundo, como se sabe. Há um exemplo interessante e recente sobre as diferenças básicas entre a cultura ocidental e a oriental: o que aparece quando discutimos a Inteligência Artificial com os orientais. Pamela McCorduck (1993), ao examinar a Inteligência Artificial, este novo ramo das ciências e técnicas, mostra que a tradição oriental sobre o "natural" e o "artificial" embora reconheça a diferença entre estas noções

\footnotetext{
4 "Todos c cada um" c a idéia de "voltado para o um" — uni versus, universal (kathólou), logo, liberdade universal.

${ }^{5} \mathrm{Na}$ verdade, nem precisaríamos voltar tanto no tempo e no espaço; bastaria recordar que os "homens brasileiros" eram escravistas e os escravos negros não eram considerados humanos. Poder-se-ia dizer que os "brasileiros" sempre tiveram os mesmos valores democráticos e de liberdade?
} 
não supõe que uma seja superior a outra. Assim, quando os ocidentais debatem a veracidade ou não da "inteligência artificial", tema polêmico e valioso para nós, com os japoneses modernos, estes "nos contemplam assombrados" (McCorduck, 1993, p.86), pois essa temática não tem sentido em sua cultura. Isto porque os orientais tendem a conceber a indissolúvel ligação de tudo com tudo - animado e inanimado, natural e artificial -, como encontramos nas concepções alquímicas ou nas cosmovisões de autores como Comenio, Roger Bacon e outros pensadores dos séculos XVI e XVII na Europa, que foram influenciados pela cultura árabe, logo oriental.

Assim, ao afirmar que os homens são sempre os mesmos em sua essência, o doutor Rubim desconhece a história humana que se fez e se faz cotidianamente, concretamente. Esse engano metodológico é próprio de uma posição transcendental que "desconhece" a realidade vivida pelos homens, que produziram modos de ser humano que não são, necessariamente, congruentes entre si e que evidenciam a multiplicidade de "naturezas humanas" produzida ao longo da história de cada uma delas.

De sua posição essencialista, o doutor Rubim julga correto estabelecer uma dada doutrina como sendo a única verdadeira. Sua posição é a negação da liberdade de investigação, da liberdade de se estabelecer outra maneira de se construir o conhecimento sobre os homens, pois nega, in limine, que se possa lançar alguma luz por meio de outros processos além ou aquém dos seus. Sustenta que só há uma maneira de falarmos "de paradigmas da educação": a que se apoia na "antropologia filosófica" que ele defende.

Certamente, tem todo o direito de defender sua posição, desde que não ataque as demais de maneira caricatural como o faz em seu artigo. Tomaremos apenas um exemplo dessa caricatura: o momento no qual o doutor Rubim fala da diferença entre as ciências positivas e as demais (ciências "não-positivas"?) que seriam as que tematizam sobre o homem em suas circunstâncias de ser, afirmando que a diferença estaria no saber quantitativo das primeiras e no saber qualitativo das demais. 


\section{Quantitativo versus qualitativo: dois tipos de ciencia?}

Quando o doutor Rubim (p.427) afirma: "...o saber na educação é um saber de elementos qualitativos, enquanto que o saber das ciências positivas é essencialmente quantitativo", expressa um engano primário. Isto porque qualquer ciência examina certas "qualidades" de determinado "objeto" que o faz existente para a investigação ou para nós.

A "quantidade" é uma dimensão da "qualidade", a de sua intensividade, de seu quantum. As ciências positivas ou empíricas e as ciências formais - lógica e matemática - tematizam "qualidades", e procuram evidenciar as "mudanças" ou "transformações" que podem ser "quantificadas" — quantum de variação que permite a manutenção desta ou daquela qualidade. De fato, são as mudanças, as variações, as transformações de algo que expõem - põem para fora - o que é este algo, pois assinala seu nascimento e perecimento ${ }^{6}$.

Tomemos, por alguns instantes, o problema do estabelecimento do "que é isto. Imediatamente começamos a alinhavar um conjunto de predicados ou categorias ou atributos ou qualidades que descreveriam o "isto"; logo, somos conduzidos a dizer o sentido de cada categoria, que nos leva a outras em um círculo infernal e infinito - de má finitude, como a de Kant. Assim, nas ciências formais - lógica e matemática - e nas ciências positivas - ou objetivas — um dos mais difíceis e laboriosos trabalhos é o da definição do "objeto", ou seja, das qualidades que se está examinando ou da rede de significações que fazem "existentes" os "objetos".

Múltiplos exemplos históricos indicam claramente que os cientistas "revolucionários" estabeleceram novos modos de ver a empiria, o "isto". Para não fugir do âmbito das ciências humanas, tomem-se as posições de Jean Piaget - no quai Lauro de Oliveira Lima se apoia e é citado, com simpatia, por Rubim - , que produziu uma revolução nas investigações epistemológicas. Piaget estabeleceu que o estudo das condições prévias para a construção dos conhecimentos científicos pode ser realizado através

* Para um exame cuidadoso sôbre as relações entre a "qualidade" e a "quantidade" sugere-se a leitura da Ciência da Lógica de Hegel. 
da investigação dos "erros" lógicos apresentados pelas crianças. Um silogismo elementar como " $\mathrm{A}=\mathrm{B} ; \mathrm{B}=\mathrm{C}$; então $\mathrm{A}=\mathrm{C}$ ", não é apresentado ou "manifestado" por crianças pequenas; logo, é preciso examinarmos as razões pelas quais não o apresentam. Podemos "medir" a distância entre a manifestação da qualidade "lógica" mencionada e sua não-manifestação. Esta "medida" são os "estágios" ou "etapas" do desenvolvimento cognitivo. A "medida" é apenas um momento da explicação, pois o que interessa, em qualquer ciência, é a exposição das razões pelas quais há variações da qualidade examinada, quando há, ou seja, quando se alcança determinar a qualidade em suas manifestações.

O doutor Rubim provavelmente se escandalizaria com a afirmação de que os "estágios" cognitivos propostos por Piaget se constituem uma "medida" do desenvolvimento do pensamento hipotético-dedutivo. Isto porque o doutor Rubim parece identificar "medida" como "escala de razão", ou seja, confunde a quantidade de uma variação de uma dada qualidade com um sistema de medida baseada na existência de "zero absoluto", pontos hierarquizados, intervalos iguais, estabilidade da unidade, o que permite qualquer operação matemática entre os valores. Por certo, a seriação dos estádios cognitivos propostos por Piaget não é uma "escala de razão". A qualidade "conceitos lógico-matemáticos" ou "conceitos de conservação de massa, peso, volume etc." varia de intensidade ao longo de um processo, e é mensurável por uma "escala ordinal", pois há uma seriação: a etapa I antecede, necessariamente, a II e esta a III, com todas as variações no interior de cada estágio cognitivo. Esta "mensuração" é uma "quantificação", no mesmo sentido dos "quantificadores lógicos" — "todo", "existe", "alguns" —, que são quantificações sem que se suponha a contagem.

No início desta seção afirmamos que o doutor Rubim não está só em seu engano. Cumpre, então, indicarmos pelo menos um outro autor que apoiaria a noção da incompatibilidade entre as ciências que examinariam a quantidade e as que examinariam, exclusivamente, a qualidade. Não é muito difícil encontrarmos um filósofo, ou um professor de filosofia, que diga, enfaticamente, que as matemáticas são, essencialmente, quantitativas. 
$\mathrm{Na}$ Enciclopédia Einaudi, que trata do tema "Dialética", o par "identidade/diferença" é examinado logo de início e, como não poderia deixar de ser, no conhecimento analítico posto pela matemática. O autor do texto da enciclopédia (v.10, p. 13) sustenta:

... durante séculos e séculos, até ao limiar dos nossos dias - e em certa medida ainda hoje - , a matemática foi muitíssimas vezes considerada como cânone de cientificidade, e de tal forma que induzia a só admitir outras ciências efectivamente como tais enquanto modeladas sobre ela e permeadas pela sua linguagem quantitativa, isso derivava (e deriva) do esforço de transpor para os conhecimentos sintéticos o caracter "universal c necessário" reconhecido nos analíticos (grifo meu).

Poderíamos citar outras passagens nas quais o autor do texto da enciclopédia retoma a noção de que a matemática é, essencialmente, quantitativa, porém o mais interessante para o nosso propósito é a passagem seguinte:

... Precisamente a matemática ilustra bem este aspecto severo do saber analítico: na verdade, ela é decorrente do mundo do qual representa aspectos Objectivos per se, como relações "quantitativas" entre (e de) objectos, verdadeiras mesmo que os homens não existissem; a relação quantitativa entre força e massas no sistema Terra/Lua, por exemplo, não é decerto apenas um modo subjetivo humano de conceber o mundo, mas sim, antes do mais, uma estrutura objectiva sempre idêntica a si própria; e isto vale também para as relações quantitativas inteiramente em abstracto, e não só para suas valências fisicas: a relação geométrica entre volume e raio de uma esfera tem uma forma de existência em si, mesmo que os homens não existissem... (v. 10, p. 13-14; os grifos e as aspas são do original).

Dizer que os "entes" matemáticos são em si porque são quantidades é uma imensa confusão, pois, sendo "em si" ouper se, expressam atributos ou qualidades de algo. A relação entre figuras geométricas são relações qualitativas - das figuras nelas mesmas - que podem ser expressas em relações diversas, entre elas a do raio e o volume da esfera, citado. A métrica da geometria é um momento da exposição da figura e não se pode alcançá-la senão depois da análise de suas qualidades. Afinal, o que 
é uma esfera? No que difere do cubo; do paralelepípedo? Quais suas propriedades - atributos, qualidades - comuns?

Além disso, o autor da Enciclopédia Einaudi "mistura" as relações da gravitação - Terra/Lua - que expressam uma determinada qualidade: a queda dos graves - pesados - , com sua expressão numérica ou de cálculo. Na verdade, antes de se estabelecer o cálculo foi preciso determinar a qualidade do objeto em pauta. Expressar a qualidade como uma relação multiplicativa e sua inversa nada mais é do que expor as modulações daquela qualidade.

O autor faz o mesmo quando examina a geometria, confundindo a "métrica" com as"morfos". A geometria examina muito mais as "morfos" — as formas - do que as "métricas", mesmo quando expressa as relações como razões e proporções - a soma dos ângulos internos de um triângulo, por exemplo, expressa a qualidade do triângulo em exame: se for plano, será $180^{\circ}$; se esférico, será variável; se hiperbólico, sempre menor do que $180^{\circ}$. O próprio autor em pauta mostra que a alteração do quinto postulado de Euclides possibilitou outras geometrías. Utiliza-se de um exemplo interessante: a distância entre duas cidades próximas pode ser medida, com certo grau de precisão, tanto pelo uso da geometria plana, como peia esférica, proposta por Gauss. Assim, para ele, se estaria obtendo a "mesma idêntica distância" (Enciclopédia Einaudi, v.10, p.20; grifo do original), mas de forma "diferente", embora a gaussiana seja a mais geral e mais correta em face da esfericidade do globo terrestre. Quer afirmar, com isto, que há identidade das medidas, quando, mesmo não considerando as diferenças existentes entre elas, poderíamos argüir sobre o instrumento de medida que pode, eventualmente, variar, jamais seriam idênticas... $\mathrm{Na}$ verdade, a geometria esférica não apenas é mais adequada para este caso, como, também, prevê a particularidade na qual se pode desprezar a esfericidade: quando a curvatura puder ser considerada igual a zero; logo, cumprem-se todas as propriedades (qualidades) da geometria plana. $\mathrm{O}$ que se altera não são os instrumentos de medida; eles podem até ser os mesmos, mas a concepção das qualidades envolvidas e uma delas é mais adequada à esfericidade da Terra. Certamente, os matemáticos sabem disso, mas os filósofos parecem desconhecer. 


\section{O homem invisível e os átomos visíveis}

O doutor Rubim e muitos outros assumem que as ciências positivas são "quantitativas"; logo, incompatíveis com o conhecimento do "humano" que seria "qualitativo". O próprio doutor Rubim nos dá uma das chaves de seu engano ao dizer:

... O homem, por exemplo, por aquilo que lhe é mais próprio, não pode ser visto, tocado, mostrado. Vêem-se, isso sim, as manifestações de seu ser mais profundo, mas aquela dimensão do ser que produz tais manifestações não é imediatamente visível. Essa dimensão, tão importante e decisiva, não aparece nos procedimentos das ciências positivas (p.427, quarto parágrafo, quarta linha em diante; grifos do original).

Poderíamos perguntar como ele sabe que existe essa "dimensão profunda", intocável, que se manifesta sem se mostrar? éo que aparece...

Aqui poderíamos opor-lhe Hegel, quando afirmava que o essencial

Mas, o engano do doutor Rubim tem outra dimensão menos profunda: ele parece desconhecer os processos de investigação das ciências positivas. Afinal, ninguém viu os elétrons, prótons e neutrons, quando se desenvolveram as teorias atômicas. Viam-se, apenas, as manifestações em placas fotográficas — os famosos "raios X" —, ou traçados na "câmara de vapor Wilson", procurando-se determinar suas "naturezas" ou "qualidades" pelas perturbações que produziam de acordo com certas estimulações ou perturbações. Como a "natureza profunda" da matéria só se deixa perceber por suas manifestações, podemos afirmar que, neste sentido, não há diferença entre as duas ordens de "fenômenos": o humano e o natural não-humano, já que só podemos "ver" suas manifestações.

O que depreendemos da afirmação do doutor Rubim é que o humano é invisível e os átomos são visíveis, uma vez que as ciências

\footnotetext{
${ }^{1}$ Notemos além disso, que o veto implícito ao estudo da "consciência" tem sua base no "positivismo" ou no behaviorismo, para os quais a "consciência" é uma "caixa preta" inacessível à investigação objetiva ou positiva- Curioso como os extremos podem se tocar...
} 
positivas criaram meios para os ver, enquanto que as ciências sobre o homem não têm condições de verificar as "profundezas humanas".

Esse caminho conduz à negação peremptória de qualquer investigação sobre qualquer objeto, pois jamais vemos a "natureza profunda" de qualquer coisa, pois sempre "vemos" o que nossas teorias ou modelos nos permitem ver. Tomemos um exemplo recente na arqueologia: a polêmica aberta sobre a antigüidade dos desenhos encontrados na caverna de Ardéche onde aparecem centenas de animais. Alex Melamid, artista plástico russo, sustenta que os desenhos são recentes, devem ter sido feitos no final do século passado, pois implicam conhecimento detalhado dos movimentos apresentados pelos animais. Este conhecimento do movimento dos animais só foi possível com a invenção da fotografia (Cf. Folha de S. Paulo, 2 abr. 1994, Cad. "Mais", p.16). O artista, educado na pintura, na história de sua arte, viu o que nós não vimos: os movimentos expressos nos desenhos dependem de um instrumento inventado no século passado. Por um lado, Melamid põe em xeque o "achado arqueológico"; por outro, apresenta um critério de validação de seu enunciado que, ao mesmo tempo, pode ser utilizado para o exame de outros desenhos arcaicos: os movimentos dos animais só puderam ser observados, objetivamente, com a fotografia. Certamente os movimentos dos animais não foram produzidos pela fotografia, a não ser que neguemos a materialidade do processo fotográfico. Podemos dizer, com Melamid, que os movimentos dos animais, o caminhar ou o correr, eram invisíveis até se obter um meio para os examinar detidamente a fotografia; a partir daí foi possível reproduzi-los, apreender sua "natureza profunda"; logo, puderam ser reproduzidos — simulados — peia pintura ou pelo desenho, não nos esquecendo dos desenhos animados.

Origens do debate contemporâneo

O centro do debate contemporâneo sobre o caráter do conhecimento científico e sua difusão foi posto peia invisibilidade dos átomos e não dos homens. Foi assim porque não é possível afirmar, com 
certeza, quais são as qualidades efetivas dos átomos; dessa maneira toda teoria atômica na ciência física - considerada a mais bem equipada entre todas as ciências positivas - é um modelo, um simulacro do real, não expressa a "verdadeira" natureza do objeto. Aceitar ou não o artefato seria, então, uma questão de moda ou de crença, ou de gosto; logo, não existiriam critérios para validação de qualquer teoria.

Dessa maneira, desde o início deste século, tem-se debatido a natureza dos conhecimentos científicos, pois novas teorias físicas mostravam-se mais adequadas do que as anteriores, quando tratavam do mundo atômico e do mundo cósmico - a teoria da relatividade de Einstein, por exemplo.

Como compreendermos, então, o processo pelo qual uma teoria recente se relaciona com a sua antecessora?

Thomas Kuhn, em 1961, apresentou seu trabalho no qual sustentava que a história das ciências indica que o processo seria, fundamentalmente, o de. substituição de paradigmas. Tomando o exemplo da Física, mostra que substituição dos paradigmas se dá por processos sociais de adesão e difusão baseados na cooptação de um número crescente de jovens cientistas, pouco comprometidos com o paradigma dominante, que, com o tempo, controlam os postos universitários, os laboratórios, os recursos financeiros, bem como o ensino da disciplina, produzindo novos manuais baseados na teoria emergente. Esse processo de adoção e difusão exclui os participantes da "velha teoria" e os que adotam uma outra "teoria alternativa qualquer". Os cientistas que discordam do "novo paradigma" não têm como fazer valer suas vozes, uma vez que as instituições estão tomadas pelo paradigma da "teoria vencedora" que aparece como sendo a "ciência normal", até que surjam novos propositores — "ciência revolucionária" - e o ciclo recomeça.

De um ponto de vista epistemológico, haveria um "corte" entre a "ciência normal" e a "ciência revolucionária", ou entre o "paradigma vigente em dado momento" e o "paradigma emergente", inexistindo continuidade ou acumulação. Esse "corte" rompe as possíveis relações entre os dois momentos, não havendo, pois, dialética entre eles ou entre 
os "paradigmas". Nao haveria superação/sublimação (Aujhebung), mas substituição de um "paradigma" por outro.

Podemos criticar a posição de Kuhn e as concepções de "corte epistemológico" ou "rupturas epistemológicas" por negarem o processo dialético da superação/sublimação que existe entre os momentos do desenvolvimento dos conhecimentos. De fato, a posição de Kuhn e de quantos defendam o "rupturismo" implica na afirmação de "estados estáticos de conhecimentos" que nao se relacionam de maneira alguma, já que um - o paradigmático — substitui, pura e simplesmente, o outro seja o senso comum, que é substituído pelo conhecimento científico; seja a substituição de paradigmas científicos. Assim, para os "rupturistas", o problema se torna o da exposição das condições que conduzem à adesão a este ou àquele paradigma. Como, então, um paradigma consegue ser hegemônico? Como se produz a substituição de paradigmas? Estas são as questões relevantes para a posição "rupturista".

Notemos que Kuhn não procurou descrever como uma teoria se valida com base em critérios racionais ou da adequação de uma teoria ao objeto de investigação - a adequado res de Kant. Descreveu como se constituem as redes de pessoas envolvidas com uma teoria que se torna paradigmática — procedimentos, relações interpessoais e institucionais. Esta descrição conseguiu abalar, ainda mais, um dos alicerces do empirismo lógico que imperava entre os cientistas anglo-saxões até a década de 60, o que sustentava a "neutralidade" do conhecimento científico. Kuhn demonstrou existir um forte componente afetivo ou subjetivo interessado, não neutro - na adoção e difusão de "teorias vencedoras" (paradigmáticas), algo similar à difusão de uma moda de vestuário.

$\mathrm{Na}$ linha de desenvolvimento dessa posição sobre a difusão de teorias científicas encontram-se os "sociólogos do conhecimento científico" como Barry Barnes, David Bloor, Steven Shapin, Harry Collins, Bruno Latour, Steve Woolgar, Karin Knoor Cetina e outros que afirmam que os fatos científicos são produtos desenvolvidos pelos cientistas e não uma exposição acurada da realidade, como desejaria o "apriorismo filosófico" (cf, por exemplo, Callón, 1989; Pickering, 1992). Estes pesquisadores foram fortemente influenciados por Kuhn e pelo "segundo" Wittegenstein. 
E inegável que uma teoria - - científica ou não - - percorre os caminhos da cooptação de novos membros, sendo que alguns destes percursos foram os descritos por Thomas Kuhn, bem como os apresentados pela "sociologia do conhecimento científico".

A partir dessa constatação tem-se sustentado que as ciências não se apóiam em critérios racionais de validação dos conhecimentos que produzem; logo, o processo de adesão nada teria de racional ou de superação racional das teorias antigas. É este silogismo que muitos tendem a estabelecer a partir das propostas seminais de Kuhn ou das proposições do "segundo Wittegenstein", que conduzem, eventualmente, ou ao relativismo radical ou ao pirronismo. Callon (1989, p. 173) mostra, por exemplo, que o laboratório de Beauregard, dedicado ao estudo de pilhas combustíveis, sustentou-se, por muito tempo, sem que tivesse apresentado qualquer resultado cientificamente valioso. Evidencia, assim, que o "objeto" de investigação se constitui sobre uma rede de relações pessoais, comerciais, de estratégia militar, levando aquele sociólogo a concluir que:

... A construção dos fatos científicos é inseparável dos atores sociais, simplesmente porque os pesquisadores colocam-se, Simultâneamente, a questão da fabricação de enunciados ou de novos dispositivos, como também de sua difusão e aceitação (Callon, 1989, p.209).

As observações de Callon indicam que os cientistas produzem os fatos que investigam, sejam ou não legítimos de um ponto de vista normativo proposto por alguma filosofia das ciências ou por uma metodologia. O relevante, aqui, é que a atividade ou prática social dos cientistas envolve relações sociais que dão sustentação ao projeto de um grupo de pesquisadores. Este projeto envolve a produção de enunciados que seriam aceitos em dado momento da vida social, ou seja, produzemse os "fatos" expressos em enunciados que os outros aceitam como tais.

O mesmo ocorre com os conhecimentos extracientíficos - que, por certo, estão presentes nas formulações apresentadas pelas ciências como são os "metafísicos", "transcendentais", "religiosos", "ideológicos". Não haveria, de um dos pontos de vista da sociologia do conhecimento 
científico, nada que distinga a adoção e a difusão de uma ideologia e de uma teoria científica, a não ser o nome das coisas.

O relativismo do conhecimento científico deve ser estendido ao próprio escopo da sociologia do conhecimento científico, uma vez que os conhecimentos produzidos pelos sociólogos também seriam negociados ${ }^{8}$ (Pickering, 1992, p. 19). Sendo assim, não teríamos como afirmar, com segurança, que os achados da sociologia do conhecimento científico são adequados à realidade dos laboratórios onde se produziram os "fatos". Chegamos, pois, a uma aporia: os enunciados da sociologia do conhecimento científico são, eles mesmos, produtos dos sociólogos que montaram a rede de significações e as múltiplas redes de relações sociais que sustentam suas posições. Dessa maneira, não poderíamos afirmar que suas teorias sejam melhores ou piores do que as de outros; de fato, eles apenas obtêm financiamentos, postos universitários, espaços editoriais etc, que outros não têm sabido negociar.

A adoção da posição detendida pela sociologia do conhecimento científico em nada difere da opção realizada por Rubim, por exemplo, que se apoia em Tomás de Aquino para afirmar o que deveria ser compreendido como paradigma da Educação. Podemos aceitar ou não o tomismo, mas não há como estabelecermos um critério que permita o esclarecimento das posições. Certamente Rubim tem todo o direito de assumir a posição que assume; poderia inclusive sustentar que sua posição é a mais correta, e não teríamos qualquer critério para negar a validade de suas proposições.

Do "como falar" ao sobre o que falamos

Os debates sobre os chamados "paradigmas" das pesquisas em Educação já foram caracterizados como sendo uma "guerra dos paradigmas" (Gage, 1989) e continuam em nossos dias tendo por centro a crítica ao que se tem denominado de "positivismo". Essas críticas

' O mesmo pode ser dito quanto à "teoria das mentalidades", que foi criticada por Lloyd, 1990. 
conduziram ao aparecimento de correntes que têm sido classificadas como a dos "pós-positivistas", "teórico-críticos" e "construtivistas" (norteamericanos), além de outras mais recentes, como, por exemplo, a dos que se autodenominam de "pós-modernos".

Alves (1993), em sua revisão do debate entre as diversas correntes metodológicas da pesquisa em Educação, indica que as divergências existentes entre os "pós-positivistas", os "teórico-críticos" e os "construtivistas" estão na compreensão que estes apresentam sobre o "relativismo" e suas conseqüências quanto às possibilidades de generalização e acumulação do conhecimento.

Para os "construtivistas", os conhecimentos em Educação jamais seriam generalizáveis e acumuláveis, uma vez que são sempre interpretações circunstanciais. Ao considerarem que as interpretações são, necessariamente, produzidas ou construídas socialmente, os construtivistas concluem pelo relativismo radical (como Callon, por exemplo). Dessa maneira, não seria possível estabelecermos os cânones de uma ciência da Educação; quando muito, poderíamos alcançar o consenso entre os interlocutores através de uma "metodologia hermenêutico-dialética" (cf. Alves, 1993, p. 14).

Por outro lado, os "pós-positivistas" e os "teórico-críticos" não admitem a "ontologia relativista" radical dos "construtivistas". Os "póspositivistas" e os "teórico-críticos" reconhecem que a realidade é socialmente construída, mas consideram que esse fato "constitui um dado importante a ser incorporado à análise, mas não traz como conseqüência o relativismo" (Alves, 1993, p. 16).

Diante do debate em torno do "relativismo", Alves encontrou um critério que possibilita compreender essas posições divergentes: pelo exame das finalidades das pesquisas conduzidas pelos pesquisadores, podemos entender a efetividade dos mesmos. Desta maneira:

.... se alguém se propõe a compreender os significados atribuídos pelos atores às situações e aos eventos dos quais participam, se tentamos descrever uma "cultura" de um grupo ou organização, no qual coexistem diferentes visões correspondentes aos subgrupos que os compõem (construtivismo), então o relativismo radical não constitui problema; se, porém, nos propomos à 
construção de teorias (pós-positivismo) ou à transformação social (teóricocríticos), a qual exige acordo em torno de decisões ou princípios que possibilitem a ação conjunta, então o relativismo passa a ser um entrave (Alves, 1993, p. 16).

Podemos dizer, então, que o "relativismo" — o pomo da discórdia - fica metodologicamente "relativizado" pelas finalidades da pesquisa que se empreende. Alves introduz, dessa maneira, um critério pragmático para a avaliação dos diversos paradigmas concorrentes: o da finalidade ou objetivo das investigações, que determinaria o grau de relativismo ontológico que poderia ser aceito pelos pesquisadores.

Poderíamos dizer, então, que os paradigmas concorrentes alcançariam certa acomodação entre si?

Austin \{apud Alves, 1993) sustenta que poderia ocorrer algum tipo de acomodação quanto a algumas questões. Alves (1993, p. 17) avalia que seria possível um ajustamento entre a utilização de conhecimentos produzidos com base em paradigmas diferentes, e a utilização, pelo pesquisador individual, de metodologias originadas por outros paradigmas, mas não vê a possibilidade de uma acomodação no nível filosófico, aquele das questões de fundo ou de fundamentação - ontologia e/ou teoria do conhecimento.

As questões de fundo postas pela pesquisa em Educação envolvem a determinação da possibilidade de todo e qualquer conhecimento, já que apresenta ou põe em foco o problema da indução. Notemos que o problema do relativismo radical e do pirronismo é bem mais sério do que a disputa sobre os significados de "paradigma", ou sobre o caráter "paradigmático" ou não das ciências sociais e, particularmente, da Educação. O cerne do debate, que emergiu da obra de Thomas Kuhn, é que qualquer teoria (científica) vale tanto quanto qualquer outra, já que sua adoção não depende de critérios lógicos, metodológicos e epistêmicos e sim dos sujeitos cooptados.

\footnotetext{
${ }^{9}$ Poderíamos dizer, também, que Alves indica as "boas razões teleológicas" dos pesquisadores em Educação, pois das finalidades diversas temos ações sociais explicadas diferentemente. Sugerimos que se leia Boudon (1987), que apresenta um interessante e valioso comentário sobre as "razões" dos atores sociais que permitiriam a construção de uma "teoria racional da ação social". Em artigo que publicamos na Revista Brasileira de Estudos Pedagógicos (n. 177, p.279-334), aplicamos esse modo de pensar, que pode ser um exemplo imediatamente acessível ao leitor.
} 
Essa conclusão é correta em um sentido: o de que qualquer teoria - sobre qualquer objeto - é, de fato, um modelo, um simulacro do fenômeno ou do "real". O "objeto do conhecimento" é sempre resultado de uma interpretação estabelecida em uma rede de significações; não há, pois, "conhecimento puro" ou "apreensão pura" do objeto. Desta constatação não decorre, necessariamente, a afirmação da impossibilidade do conhecimento científico - pirronismo - , nem que qualquer teoria deva ser considerada como válida - relativismo radical. Isto porque, o próprio das ciências é a permanente crítica dos enunciados, produzindo, historicamente, a descentração do sujeito, e estabelecendo, por este processo, o reconhecimento do lugar do sujeito e do objeto na relação "conhecimento cientifico". Entre essas críticas estão as que esclarecem o lugar da "indução" na produção do conhecimento científico: se é correto dizer que não há "verdade absoluta", é também correto sustentar que o conhecimento científico se faz no curso de sua história, ou seja, não é em si e por si, faz-se em sua historicidade. Apenas de um ponto de vista extra-histórico - transcendental, caso queiramos - é possível contestar a historicidade do conhecimento científico, porque não é possível afirmar a eternidade de seus "modelos" ou "teorias".

\section{Concluindo}

O problema da investigação em Educação não é o de que possa ou não ser "paradigmática", nem que é preciso instituir uma "antropologia filosófica" que dê sentido único à noção de paradigma, como quer Rubim.

O problema central, de fato, encontra-se na determinação da possibilidade da indução, ou seja, se é possível construirmos modelos adequados ao real a partir de nossas experiências. A epistemologia clássica nega essa possibilidade, mas o racionalismo historicista demonstra que a indução é possível, necessária para qualquer conhecimento e que sem ela não seria possível a vida humana tal como a conhecemos. Deste ponto de vista, o conhecimento científico é possível em qualquer área que se deseje, desde que se utilize a lógica adequada ao objeto, como o físico se utiliza da geometria que melhor seja adequada ao seu objeto (cf. Da Costa, 1980; Mazzotti, 1992; Alves, 1993). Logo, o "objeto" é uma construção histórica 
que se determina pela crítica metodológica, lógica e epistêmica desenvolvida no interior de cada ciência, ou, dizendo de outra maneira, a objetividade é um processo que se constrói sem que possamos afirmar quando termina, nem onde começa. Nesse processo os homens alteram suas condutas e sua natureza, tornando-se cada vez menos presos às limitações da "subjetividade imediata" — Hegel —, no movimento de "universalização" permitida pelo desenvolvimento das ciências. A inteligência desenvolve-se, torna-se mais poderosa, com o desenvolvimento das ciências, com o processo de descentração do sujeito, pois a "formação da inteligência ...prossegue com o desenvolvimento do pensamento científico" (Piaget, 1975, p.269).

O doutor Rubim, que é "essencialista", supõe que o homem é sempre o mesmo, mas temos todas as evidências de que há tantas naturezas humanas quantas são as culturas, sendo que a cultura assumida pelo nosso autor é uma das possíveis, não a única e nem a paradigmática (no sentido grego).

Finalmente, ao compreendermos que a manifestação ou a conduta de alguém expõe o que ele é em dado momento, estamos afirmando que somos um processo de equilibração instável cujo percurso futuro é imprevisível... como têm concluído as "ciências positivas" (teorias dos sistemas dinâmicos que têm sido apelidadas de "caos") ao analisarem as "qualidades" que se alteram, modulam, segundo a intensidade das interações de um sistema complexo dinâmico.

\section{Referências bibliográficas}

ALVES, A. J. Paradigmas da pesquisa em Educação: uma avaliação dos desenvolvimentos recentes. Caxambu, 1993. mimeo. Apresentado na $16^{\mathrm{a}}$ Reunião Anual da ANPEd.

CALLON, M. La science et ses réseaux: genèse et circulation des faits scientifiques. Paris: Découvert/CNRS, 1989.

DA COSTA, N.C.A. Ensaio sobre os fundamentos da Lógica. São Paulo: Hucitec: Editora da Universidade de São Paulo, 1980.

ENCICLOPÉDIA EINAUDI. Lisboa: Imprensa Nacional: Casa da Moeda, 1988. v.10: Dialéctica.

R. bras. Est. pedag., Brasília, v.74, n. 178, p.681-700, set./dez. 1993 
GAGE, N.C. The paradigm wars and their aftermath: a "historical" sketch of research on teaching since 1989. Educational Researcher, v. 18, n.7, p 4$10,1989$.

LLOYD, G.E.R. Demystifying mentalities. Cambridge: Cambridge University Press, 1990.

MCCORDUCK, P. Inteligencia artificial: un aperçu. In: GRAUBARD, Stephen R. El nuevo debate sobre la inteligencia artificial: sistemas simbólicos y redes neuronales. Trad. por Carlos Reynoso. Barcelona: Gedisa, 1993.p.81101 .

MASTERSON, M. A natureza do paradigma. In: LAKATOS, I., MUSGRAVE A. (Eds.) A crítica e o desenvolvimento do conhecimento. São Paulo' Cultrix, 1979.

MAZZOTTI, T B. Pedagogia, elementos para sua determinação. Cuiabá: UFMT: Instituto de Educação, 1992. p.45-73: Sujeito epistêmico, na teoria piagetiana, seria um simulacro? Anual da ANPEd, 1993.

Estatuto de cientificidade da Pedagogia. XVII Reunião

PIAGET, J. Introducción a la epistemologia genética. Trad. por M.T Cevasco e V. Fischman. Buenos Aires: Paidós, 19/5. t.3: El pensamiento biológico, psicológico y sociológico.

PICKERING, A.(Ed.) Science as practice and culture. Chicago: University of Chicago Press, 1992.

VERNANT, J.P., VIDAL-NAQUET, P. Mito e tragédia na Grécia Antiga. Trad.: Bertha Halpen Gurovitz. Colab.: Hélio Gunvitz. São Paulo: Brasiliense, 1991.

Recebido em 24 de abril de 1995.

Tarso Bonilha Mazzotti, doutor em Educação pela Universidade de São Paulo (USP), é professor adjunto da Faculdade de Educação da Universidade Federal do Rio de Janeiro (UFRJ). 